\title{
Horizontal deformation in South Korea from permanent GPS network data, 2000-2003
}

\author{
Ahmed M. Hamdy ${ }^{1,2}$, Pil-Ho Park ${ }^{1}$, and Hyung-Chul Lim ${ }^{1}$ \\ ${ }^{1}$ Korea Astronomy Observatory, 61-1, Hwaam-dong, Yuseong-gu, Daejeon 305-348, South Korea \\ ${ }^{2}$ Geodynamic Department, National Research Institute of Astronomy and Geophysics, Helwan, Cairo, Egypt
}

(Received October 5, 2004; Revised January 30, 2005; Accepted February 1, 2005)

\begin{abstract}
Analysis of continuous GPS data 2000-2003 at 50 stations of the Korean GPS Network (KGN) suggests that the southern part of the Korean peninsula is tectonically more stable than other regions in the Eastern Asia. The average velocity was $\sim 1.5 \mathrm{~mm} / \mathrm{yr}$ and the average overall strain rate was around $-0.3 \times 10^{-9} \mathrm{str} / \mathrm{yr}$. The obtained velocity field indicates the presence of anticlockwise rotation of the whole region with respect to Daejeon station (DAEJ), in the central part of South Korea. It also showed that KM-OB (Kyonggi Massif and the Okchon Basin) and YM-TB (Yeongnam Massif and Taebaeksan Basin) have left-lateral shearing movements. Both movements were confirmed by the deformation analysis of the KGN horizontal velocity field using the infinitesimal plate theory. The results show that South Korea moves toward the WNW direction with a velocity of $0.9 \mathrm{~mm} / \mathrm{yr}$ with a slow anticlockwise rotation. The strain field in South Korea indicates the existence of both compression and tension. The compression and extension axes have WSW-EWE and NNW-SSE directions, respectively.
\end{abstract}

Key words: GPS, Korean peninsula, horizontal deformation, KGN, tectonic, strain field in South Korea.

\section{Introduction}

The Korean peninsula is located close to the eastern Asian active margin, and is located between the North and South China Blocks and Japanese island arcs as a part of the Eurasian or Amurian Plate. Two major factors control the tectonics of eastern Asia: 1) subduction of oceanic plates (the Pacific Plate and the Philippine Sea Plate), and 2) the collision of the Indian Plate with the Eurasia Plate resulting in the eastward expulsion of relatively small continental plates (Molnar and Tapponnier, 1975). Generally, the Korean peninsula is divided into three main Archaean to midProterozoic blocks (Hurley et al., 1973; Reedman and Um, 1975; Ernst et al., 1988), which are from north to south: Nangrim-Pyongnam Massif (PB), Kyonggi Massif (KM), and Yeongnam Massif (YM). The Nangrim-Pyongnam Massif and the Kyonggi Massif are separated by the Imjingang Belt along the western part of the North Korea-South Korea border line. The Yeongnam Massif is separated from Kyonggi Massif by the Okchon Belt (Fig. 1). Past studies (e.g., Cluzel et al., 1990, 1991a, b; Cluzel, 1992) suggested that the Kyonggi Massif (South China Block) and the Yongnam Massif (North China Block) collided in late Permian to early Triassic. Chough et al. (2000) further suggested that KM-OB (the Kyonggi Massif and Okchon Belt) began to accrete to YM-TB (Yongnam Massif and Taebaeksan Basin) located east of the Pyongnam Basin.

Recent tectonic evolution of the Korean Peninsula has been discussed in several publications using different geophysical approaches. Kyung (1993) examined the corre-

Copy right(c) The Society of Geomagnetism and Earth, Planetary and Space Sciences (SGEPSS); The Seismological Society of Japan; The Volcanological Society of Japan; The Geodetic Society of Japan; The Japanese Society for Planetary Sciences; TERRAPUB. lation between the seismicity and the gradient map of the Bouguer gravity anomaly in the Korean peninsula and suggested that the tectonic boundaries in Korea are associated with fault lineaments. Choi et al. (1999) divided South Korea into seven zones, considering the characteristics of the Bouguer anomaly map. These seven zones include four major zones, Kyonggi Massif, Okchun Basin, Yeongnam Massif and Taebaeksan Basin, and three other local zones. Kim and Lee (2000) divided the Korean peninsula into four zones by considering seismic activity, geology, major faults, and tectonic settings. Two of them are located in South Korea; one covers Kyonggi Massif while the second covers the Yeongnam Massif, Okchun Basin, and Taebaeksan Basin.

Generally speaking, the recent tectonic environment in South Korea, shown in Fig. 1, can be understood by considering the two massifs, i.e. Kyonggi Massif and Yeongnam Massif, and two basins, i.e. Okchun Basin and Taebaeksan Basin, separated by the five major faults, i.e. Bongwhajae, New-Okchun1, New-Okchun2, Taebk-seogchun and Yangsan.

Space geodetic techniques, such as Global Positioning System (GPS), have been used as a useful tool in investigating global plate motions and regional tectonic movements (Argus and Heflin, 1995; Larson et al., 1997). A number of tectonic studies using GPS have been done for the eastern Asia covering Japan, China and Siberia (Kato et al., 1998; Shen et al., 2000; Holt et al., 2000). Compared with other regions in eastern Asia, geodetic or neo-tectonic characteristics of the Korean Peninsula have not been well known because of the lack of space geodetic facilities. In spite of such a difficulty, several studies have been recently done, e.g. Park et al. (2001) and Hamdy et al. (2004).

By 1992, precise surveying with GPS started in South 


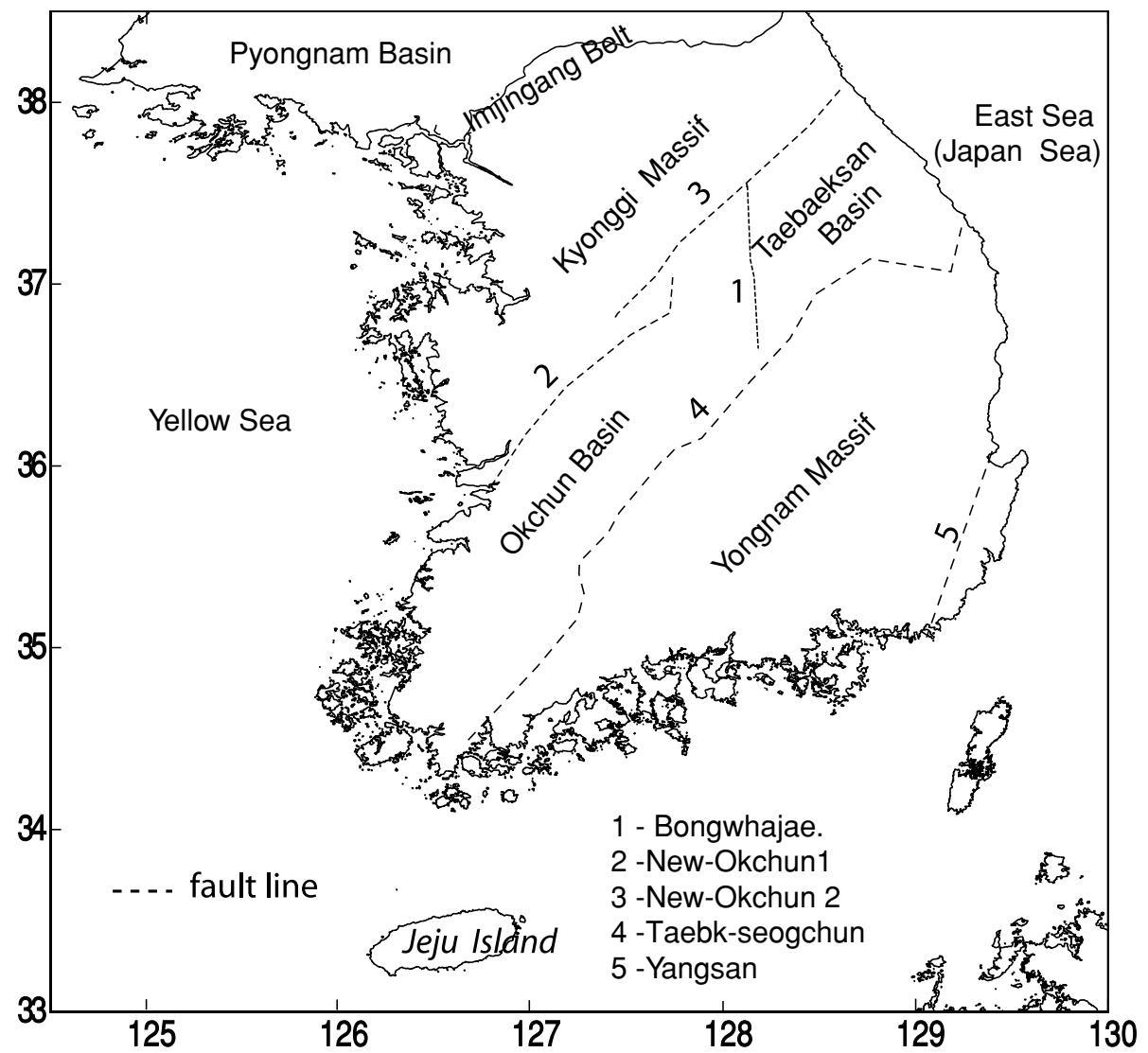

Fig. 1. Recent tectonic setting of South Korea.

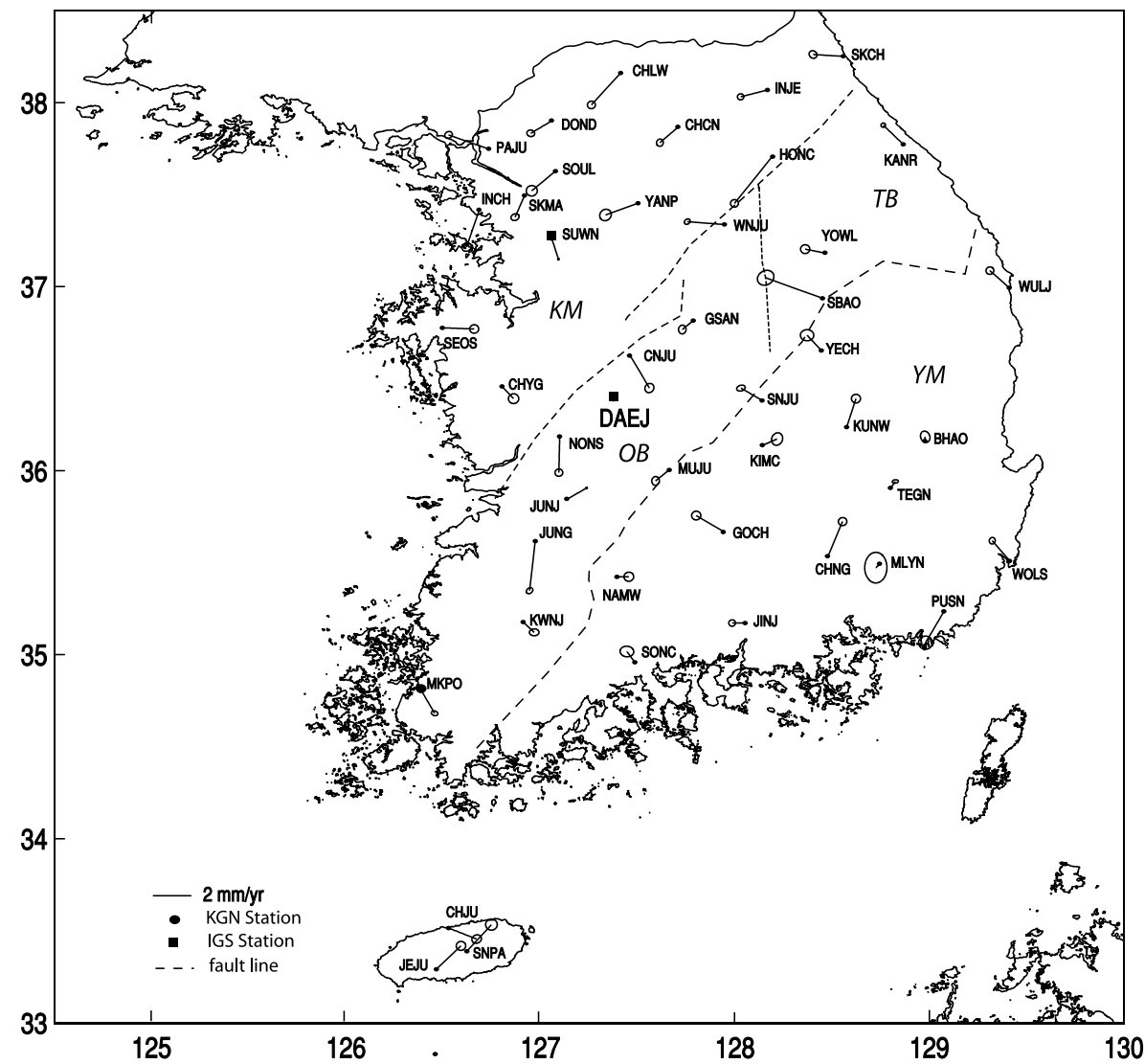

Fig. 2. Map showing the observed velocity field in the Korean peninsula. The error ellipses show with 95\% confidence limits. Abbreviations of tectonic blocks are as follows; $\mathrm{TB}=$ Taebaeksan $\mathrm{Basin}, \mathrm{KM}=$ Kyonggi Massif, $\mathrm{YM}=$ Yongnam Massif, and $\mathrm{OB}=\mathrm{Okchon} \mathrm{B}$ asin. 

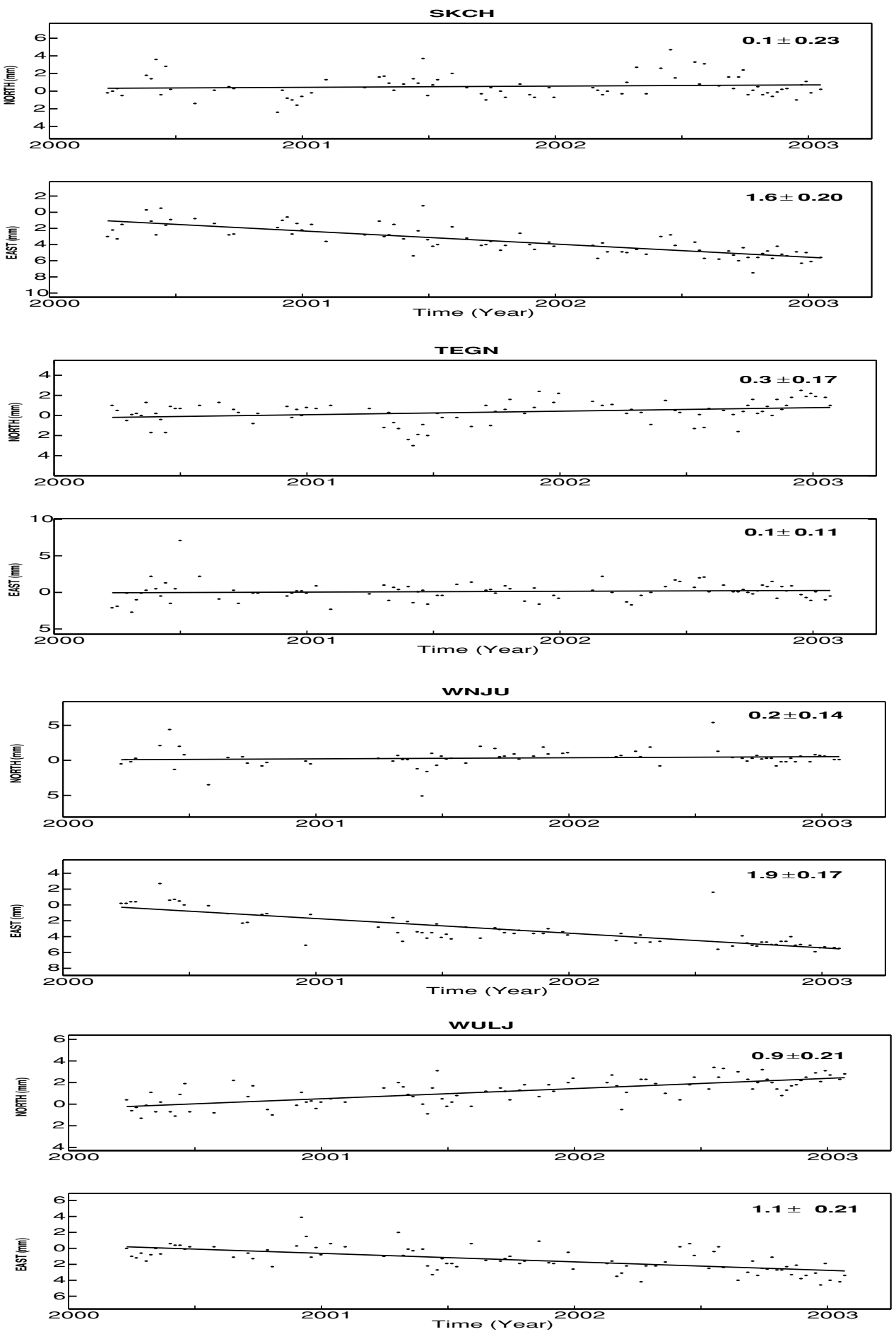

Fig. 3. Time series of horizontal coordinates for some selected sites with respect to the DAEJ station. Solid lines are the best fit lines for temporal changes of the east and north components.

Korea with the establishment of the first permanent GPS station at the Korea Astronomy Observatory (KAO). Then, the Korean GPS Network (KGN) was established by 2000 with 70 stations as a collaboration by KAO, the Korean research Institute of Geosciences And Mineral resources (KIGAM), Ministry Of Governmental Administration and Home Affairs (MOGAHA), Ministry of Maritime Affairs and Fisheries (MOMAF), and National Geographic Information Institute (NGII). The KGN data quality has been evaluated by Park et al. (2002). Their results show that among the KGN stations, 20 stations are instable and should be excluded from farther geodetic studies. Therefore, we use the GPS data from the $50 \mathrm{KGN}$ stations to investigate the horizontal velocities in South Korea and their relationship with the tectonic settings of Korea.

\section{Data Analysis}

In the present study, we analyzed three years of data (April 2000 to March 2003) from fifty GPS sites, constructed on geologically stable monuments (pillars). Two 
Table 1. The estimated deformation parameters. $\omega$ is the angular velocity $\left(10^{-7}\right.$ degree/year), $T$ is the translation rate (mm/yr), $\beta$ is the translation azimuth (degree), $\alpha$ is the azimuth of the principle strain rate of tension (degree), $\mathrm{e}_{1}$ and $\mathrm{e}_{2}$ are the rates of principle strains $\left(10^{-7}\right.$ strain/year), $\alpha$ and $\beta$ are measured clockwise from the north. TB had too few stations and we did not calculate its strain rate. The used velocities in the infinitesimal plate calculation are the KGN velocities with respect to DAEJ. TB=Taebaeksan Basin, $\mathrm{KM}=\mathrm{Kyonggi}$ Massif, $\mathrm{YM}=\mathrm{Yongnam} \mathrm{Massif}$, $\mathrm{OB}=\mathrm{Okchon}$ Basin, the blocks were taken from Chough et al. (2000).

\begin{tabular}{lcccccccc}
\hline Block & $\omega$ & $T$ & $\beta$ & Dilatation & Shear & $\mathrm{e}_{1}$ & $\mathrm{e}_{2}$ & $\alpha$ \\
\hline KM & -4.5 & 1.3 & -103 & 0.5 & 0.3 & 0.38 & 0.11 & -22 \\
OB & -8.5 & 1 & -163 & -0.1 & 0.2 & 0.47 & -0.19 & -12 \\
TB & - & - & - & - & - & - & - & - \\
YM & 2.8 & 0.7 & -11 & -0.5 & 0.1 & 0.38 & -0.89 & 15 \\
KM+OB & -5.1 & 1 & -120 & 0.2 & 0.4 & 0.28 & -0.66 & -28 \\
YM+TB & 1.2 & 0.8 & -20 & -0.2 & 0.1 & 0.52 & -0.74 & 7 \\
Korea & -6.8 & 0.9 & -87 & -0.3 & 0.8 & 0.37 & -0.47 & -15 \\
\hline
\end{tabular}
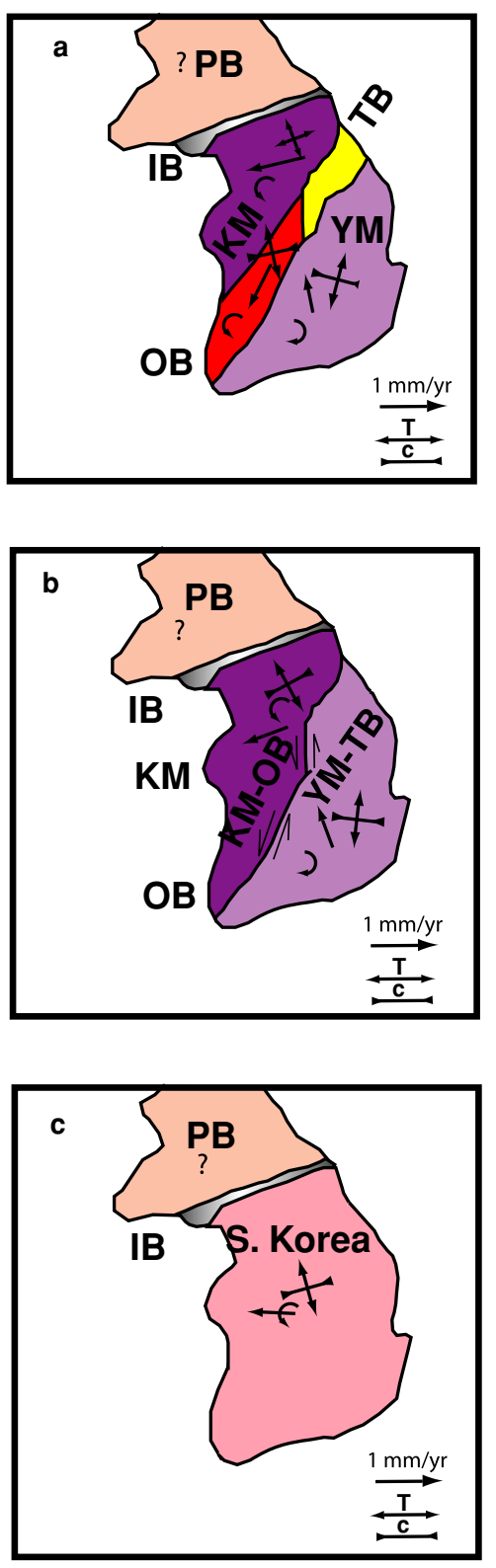

Fig. 4. Deformation of South Korean blocks (2000-2003). A, B and C show cases assuming 4, 2 and 1 blocks, respectively. Arrows are not to scale (for the values see table 1). Abbreviations are the same as in Fig. 2. of them (DAEJ and SUWN) are International GPS Service (IGS) stations, (Fig. 2). The Bernese software version 4.2, IGS final orbits, satellite clock offsets, and IGS Earth orientation parameters were used for data processing. The tropospheric delays were estimated and the quasi-ionosphere free (QIF) strategy was employed for the ambiguity resolution (Beutler et al., 2001). Due to the large amount of data collected by the network and limited computer resources (memory and computing time), 8 clusters of observations had been adopted and a parallel processing strategy was implemented using the Bernese Processing Engine (BPE). To unify the datum definition for the KGN stations and to process all the clusters in one reference frame (ITRF97), three tie stations DAEJ, SUWN and JUNJ were incorporated in each cluster. The ADDNEQ program of the Bernese software was used to combine all the normal equations. The cluster solutions are first obtained on daily basis, and then weekly solutions were produced. These normal equations were combined into free solution for the purpose of outlier detection. After the exclusion of all the outliers, a solution was generated fixing the DAEJ station in the ITRF97 reference frame.

Finally, the station velocities relative to DAEJ were estimated by using least squares linear fitting for the station position time series after removing the weekly solutions containing outliers. Figure 2 represents the multiyear velocities of the KGN together with their error ellipses showing the $95 \%$ confidence limits. Figure 3 shows examples of the obtained time series.

\section{Discussion}

The obtained horizontal velocity field (Fig. 2) in South Korea reveals that: 1) the average velocity $(1.5 \mathrm{~mm} / \mathrm{yr})$ is relatively small reflecting the high stability and small seismic activity of the Korean Peninsula (see KMA, 2001; Hamdy and Jo, 2002), 2) Most of the Kyonggi Massif (KM) stations move toward southwest, 3) Taebaeksan Basin (TB) stations move toward northwest, 4) Okchon Basin (OB) stations move toward south to southeast, and 5) Yeongnam Massif (YM) stations move toward northeast. A closer look at the velocity map (Fig. 2) suggests that South Korea rotates anticlockwise and that KM-OB and YM-TB blocks 


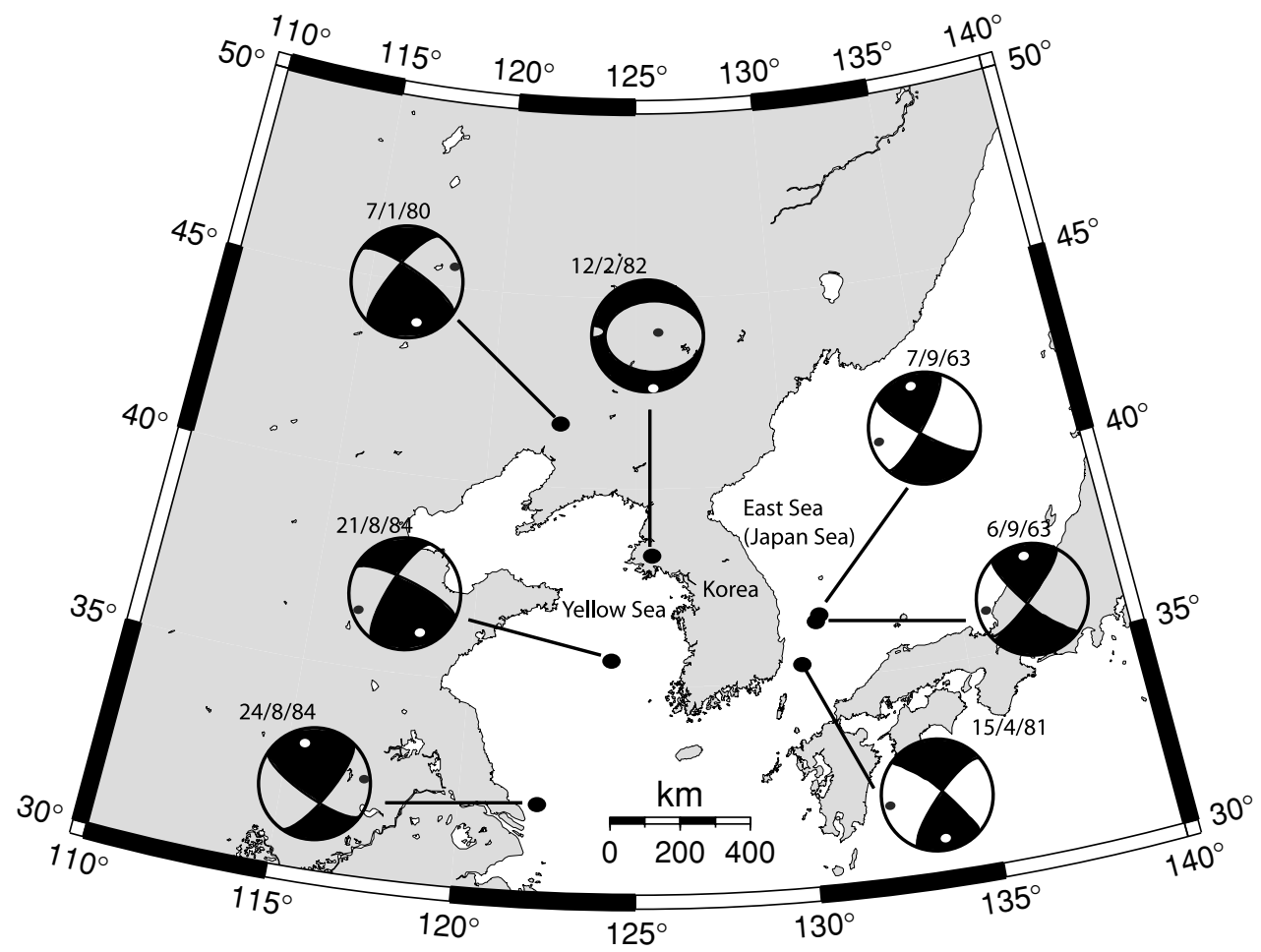

Fig. 5. Focal mechanisms of recent major earthquakes in and around the Korean Peninsula (Jun, 1990). Empty and full small circles in the focal sphere represent $\mathrm{T}$ and $\mathrm{P}$ axes, respectively.

show slow left-lateral movements.

In order to study present deformation of South Korea, the obtained horizontal velocities were analyzed using the infinitesimal plate theory (Harvey, 1985; Grant, 1990; Hamdy, 2001). There we assume that the deformation is infinitesimal when the changes in the line elements between any two points are much less than the distance between these points. This assumption is reasonable for crustal deformation in the geodetic time window (up to 100 years). The general equation used for the strain calculation is $X_{2}=(S+R) X_{1}+T$, where $X_{1}$ and $X_{2}$ are the position vectors, $S$ is a symmetric matrix representing the strain tensor, $R$ is the matrix of the rigid body rotations, and $T$ is the translation of the whole body (any body can translate, rotate and/or deform if exposed to force fields).

We study here three cases of deformation analysis: four blocks, two blocks and one block (deformation of the whole South Korea). In the first case, we divide South Korea into 4 blocks according to the geological settings, i.e. two massifs KM and YM and two basins OB and TB (Hurley et al., 1973; Reedman and Um, 1975; Ernst et al., 1988). Our deformation analysis results (Fig. 4(a), Table 1) show that the $\mathrm{KM}$ and $\mathrm{OB}$ rotate anticlockwise, while the $\mathrm{YM}$ rotates clockwise. The maximum tensile strain was found to be $5 \times 10^{-8} \mathrm{str} / \mathrm{yr}$ in $\mathrm{KM}$, while OB and YM had compressional strains. On the other hand, the maximum shear strain rate was $3 \times 10^{-8} \mathrm{str} / \mathrm{yr}$ in $\mathrm{KM}$. The deformation parameters for TB were not calculated because of inadequate amount of data.

Our velocity map (Fig. 2), along with the hypothesis of continent-continent collision between the KM-OB and YMTB (Cluzel et al., 1990, 1991a, b; Cluzel, 1992; Chough et al., 2000), encourages us to consider the two blocks case. The results (Fig. 4(b) and Table 1) show that KMOB translate toward WSW and rotate anticlockwise, while YM-TB translate toward NNW and rotate clockwise, that is, KM-OB and YM-TB show left-lateral movements. The strain in KM-OB was tensile $\left(2 \times 10^{-9} \mathrm{str} / \mathrm{yr}\right)$, while that in YM-TB showed contraction $\left(-2 \times 10^{-9} \mathrm{str} / \mathrm{yr}\right)$.

Finally, the overall deformation parameters in South Korea were investigated. Our results show WNW translation as fast as $0.9 \mathrm{~mm} / \mathrm{yr}$ accompanied with anticlockwise rotation. The principle axis of tension was NNW-SSE while the compressional axis was WSW-ENE (Fig. 4(c) and Table 1). These directions can be compared with earthquake mechanisms as shown in Fig. 5. Jun (1990) determined focal mechanisms and source parameters of seven shallow earthquakes with magnitudes grater than 5.1 and less than 6.3. His results show that the earthquake mechanisms in and around the Korean peninsula were predominantly strike-slip with small amount of thrust components. Their $\mathrm{P}$ and $\mathrm{T}$ axes were ENE-WSW $\left(\mathrm{N} 71^{\circ} \mathrm{E}\right)$ and NNW-SSE direction, respectively. Furthermore, Jun et al. (1999) investigated 22 large intra-plate earthquakes in and around the Korean Peninsula (from 1963 to 1996), and concluded that the average $\mathrm{P}$ axis is almost horizontal and in the ENE-WSW direction. The observed overall compressional strain rate in South Korea was about $0.3 \times 10^{-9} \mathrm{str} / \mathrm{yr}$, and the shear strain rate was about $8 \times 10^{-9} \mathrm{str} / \mathrm{yr}$. Such strain rates are about two orders of magnitude smaller than those in active areas such as Japan (EL-Fiky, 2000), a result consistent with the smaller seismicity of the Korean Peninsula. 


\section{Conclusion}

The observed horizontal velocity field in South Korea revealed that: 1) the average horizontal velocity is as small as $1.5 \mathrm{~mm} / \mathrm{yr}$ reflecting the high stability and small seismic activity of South Korea, 2) southern part of the Korea Peninsula rotates anticlockwise, and 3) the KM-OB (Kyonggi Massif and the Okchon Basin) and YM-TB (Yeongnam Massif and Taebaeksan Basin) have left-lateral relative movements.

The strain analyses in South Korea showed that: 1) KMOB translates toward the WSW direction with slight anticlockwise rotation, while YM-TB translate toward NNW with small clockwise rotation, 2) the southern part of the Korean Peninsula moves toward WNW by $0.9 \mathrm{~mm} / \mathrm{yr}$ and rotate clockwise by $\left.-6.8 \times 10^{-7} \mathrm{deg} / \mathrm{yr}, 3\right)$ the principle axis of tensile strain in South Korea is NNW-SSE direction (compressional axis is WSW-ENE), which agrees with the earthquake source mechanisms, and 4) the average strain rate in South Korea is as small as $-0.3 \times 10^{-9} \mathrm{str} / \mathrm{yr}$ (compression).

The results, obtained with three years of observations at 50 permanent GPS stations, revealed tectonic framework of the southern part of the Korean peninsula. Future velocity data with longer time span, together with detailed studies of other geophysical techniques (e.g., gravimetry, seismology and magnetism) will help us fully understand the plate tectonic setting of the Korean Peninsula.

Acknowledgments. The authors thank NGII and MOGAHA for contributing their GPS data. Also KIGAM is acknowledged for the fault line data contribution. The critical reviews by Drs. Hiroaki Takahashi and Takeo Ito, together with the kind support and advice of Prof. Dr. Kosuke Heki, much improved the manuscript. This work was supported by the Korean Ministry of Science and Technology via grants M2-0306-01-0004 and M6-0404-00-0018.

\section{References}

Argus, D. F. and H. B. Heflin, Plate motion and crustal deformation estimated with geodetic data from Global positioning system, Geophys. Res. Lett., 18, 1973-1976, 1995.

Beutler, G. F. et al., Bernese GPS software Version 4.2, Astronomical institute, University of Bern, 2001.

Choi, K. S., G. V. R. Kumar, and K. Y. Kim, Qualitative interpretation of Bouguer anomaly in the south part of the Korean peninsula, Geosciences Journal, 3, 1, 49-54, 1999.

Chough, S. K., S. T. Kwon, J.-H. Ree, and D. K. Choi, Tectonic and sedimentary evolution of the Korean peninsula: review and new view, J. Earth-Science Reviews, 52, 175-235, 2000.

Cluzel, D., Late Paleozoic to early Mesozoic geodynamic evolution of the circum-Pacific orogenic belt in South Korea and Southwest Japan, Earth Planet Sci. Lett., 108, 289-306, 1992.

Cluzel, D., J.-P. Cadet, and H. Lapierre, Geodynamics of the Ogcheon Belt (South Korea), Tectonophysics, 183, 41-56, 1990.

Cluzel, D., B.-J. Lee, and J.-P. Cadet, Indosinian dextral ductile fault system and synkinematic plutonism in the southwest of the Ogcheon belt (South Korea), Tectonophysics, 194, 131-151, 1991a.

Cluzel, D., L. Jolivet, and J.-P. Cadet, Early middle Paleozoic intraplate orogeny in the Ogcheon belt, South Korea: a new insight on the Paleozoic buildup of east Asia, Tectonics, 10, 1130-1151, 1991b.

EL-Fiky, S. G., Elastic and inelastic strains in the Japanese Islands deduced from GPS dense array, Earth Planets Space, 52, 1107-1112, 2000.
Ernst, W. G., R. Cao, and J. Jiang, Reconnaissance study of Precambrian metamorphic rocks, northwestern Sino-Korean shield, Peoples Republic of China, Geol. Soc. Am. Bull., 100, 692-701, 1988.

Grant, D. B., Computation of terrestrial and GPS data for earth deformation studies, Unisurv S-2, School of Surveying, University N. S. W., 11-30, 1990.

Hamdy, A. M., Recent crustal movement studies in Sinai Peninsula and around the Gulf of Suez using GPS technique. Ph.D. thesis, Faculty of Engineering, Zagazig University, Benha Branch, Egypt, 2001.

Hamdy, A. M. and B.-G. Jo, Proposed program for monitoring recent crustal movement in the Korean Peninsula, Journal of Korean Geophysical Society, 5, 4, 283-292, 2002.

Hamdy, M. A., P.-H. Park, and B-G. Jo, Preliminary crustal movement study around the Honam shear zone and Okchon Belt (South Korea) using GPS observation, Geosciences J., 8, 109-112, 2004.

Harvey, B. R., The computation of VLBI and ground data for geodesy and geophysics, Unisurv S-2, School of Surveying, University N. S. W., 1985.

Holt, W. E., N. Chamot-rooke, X. Le Pichon, A. J. Haines, B. Shen-Tu, and J. Ren, Velocity field in Asia inferred from Quaternary fault slip rates and Global Positioning System observations, J. Geophys. Res., 105, 19185-19209, 2000.

Hurley, P. M., H. W. Pinson, and J. H. Lee, Middle Precambrian and older apparent age values in the basement gneisses of South Korea and relations with Southern Japan, Geol. Soc. Am. Bull., 84, 2299-2304, 1973

Jun, M.-S, Tectonic implication of shallow earthquakes in and around the Korean Peninsula, ACTA Universities Uppsaliens, comprehensive summaries of Uppsala dissertation from the Faculty of Science, 285, 1-30, 1990.

Jun, M.-S, J.-S. Jeon, and L.-Y. Che, Earthquake mechanism of Korean Peninsula, Proceedings of EESK conference, Published by the J. of Earthquake Engineering Society of Korea, 3, 2, 58-63, 1999 (in Korean with English abstract)

Kato, T., Y. Kotake, S. Nakano, J. Beavan, K. Hirahara, M. Okada, M. Hoshiba, O. Kamigaichi, R. B. Feir, P.-H. Park, M. D. Gerasimenko, and M. Kasahara, Initial results from the WING, the continuous GPS network in the west Pacific area, Geophys. Res. Lett., 25, 369-372, 1998.

Kim, S. G. and K. S. Lee, Seismic risk map of Korea obtained by using South and North Korea Earthquake catalogues, J. of Earthquake Engineering Society of Korea, 4, 1, 13-34, 2000.

Korean Meteorological Administration, Earthquake observation report 1978-2000, Korean Meteorological Administration Publications, 2001.

Kyung, B. D., Correlation of earthquake occurrence with topography and lineaments in South Korea, J. of Korean Earth Science Society, 14, 482491, 1993.

Larson, K. M., J. T. Freymueller, and S. Philipsen, Global plate velocities from the Global Positioning System, J. Geophys. Res., 102, 9961-9998, 1997.

Molnar, P. and P. Tapponnier, Cenozoic tectonic of Asia: effects of a continental collision, Science, 189, 419-426, 1975.

Park, P.-H., U. Chwae, Y-W. Han, and H. Choi, Preliminary GPS results and a possible neotectonic interpretation for South Korea, Earth Planets Space, 53, 937-941, 2001.

Park, K.-D., K.-N. Kim, H.-C. Lim, and P.-H. Park, Evaluation of data quality of permanent GPS stations in South Korea, Journal of Astronomy and Space Sciences, 19, 4, 367-376, 2002.

Reedman, A. J. and S. H. Um, Korean Inst. Energy resource Seoul, 139, 1975.

Shen, Z.-K., C. Zhao, A. Yin, Y. Li, D. D. Jackson, P. Fang, and D. Dong, Contemporary crustal deformation in east Asia constrained by Global Positioning System measurements, J. Geophys. Res., 105, 5721-5734, 2000 .

A. M. Hamdy (e-mail: amhamdy_eg@yahoo.com), P.-H. Park, and H.C. $\operatorname{Lim}$ 